\title{
Pendidikan Kesehatan tentang Terapi Komplementer pada Masa Nifas
}

\author{
Fatihatul Hayati \\ Program Studi SI Kebidanan dan Profesi Ners, STIKes Baiturrahim Jambi \\ email: fatihatulhayatianam@gmail.com
}

Submitted :17/12/2020

Accepted: 16/10/2021

Published:28/01/2022

\begin{abstract}
Complementary midwifery services are part of the application of complementary and alternative medicine in midwifery services. Complementary midwifery services are an option for midwives and women to reduce medical interventions during pregnancy and childbirth and the puerperium, and based on experience this is quite helpful. However, most of these therapies are not considered meaningful in conventional medicine. This is due to the scarcity of published clinical evidence and information regarding the effectiveness of complementary obstetric services in pregnancy, childbirth and the puerperium. The use of complementary therapies in the field of midwifery must be proven safe by research. Although traditional / complementary medicine is relatively safer, it does not mean that it does not pose a risk, for that mothers must have adequate knowledge about the use of safe complementary therapies during the postpartum period. This community service is carried out in the work area of the Putri Ayu Community Health Center with the largest target number of pregnant women, so it is hoped that the mother will get correct information about the use of complementary therapies during the postpartum period since pregnancy, so that mothers can leave harmful therapies and utilize complementary therapies appropriately.
\end{abstract}

Keywords: complementary therapies, knowledge, puerperium

\begin{abstract}
Abstrak
Pelayanan kebidanan komplementer merupakan bagian dari penerapan pengobatan komplementer dan alternatif dalam pelayanan kebidanan. Pelayanan kebidanan komplementer merupakan pilihan bagi bidan maupun perempuan untuk mengurangi intervensi medis saat hamil dan melahirkan serta masa nifas, dan berdasarkan pengalaman hal tersebut cukup membantu. Namun, sebagian besar terapi ini tidak dianggap bermakna dalam pengobatan konvensional. Hal ini disebabkan oleh kelangkaan bukti klinis dan informasi yang diterbitkan sehubungan dengan efektivitas pelayanan kebidanan komplementer pada kehamilan, persalinan dan nifas. Pemanfaatan terapi komplementer dalam bidang kebidanan harus dibuktikan keamanannya dengan penelitian. Meskipun pengobatan tradisional/ komplementer relatif lebih aman namun bukan berarti tidak menimbulkan risiko, untuk itu ibu harus memiliki pengetahuan yang mumpuni tentang pemanfaatan terapi komplementer yang aman selama nifas. Pengabdian masyarakat ini dilaksanakan di wilayah kerja puskesmas Putri Ayu dengan jumlah sasaran ibu hamil terbesar, sehingga diharapkan ibu mendapatkan informasi yang benar tentang pemanfaatan terapi komplementer pada masa nifas sejak kehamilan, agar ibu dapat meninggalkan terapi yang merugikan dan memanfaatkan terapi komplementer dengan tepat.
\end{abstract}

Kata kunci: ibu nifas, pengetahuan, terapi komplementer

\section{PENDAHULUAN}

Terapi komplementer merupakan bidang ilmu kesehatan yang berperan dalam menangani berbagai penyakit dengan teknik tradisional, yang juga dikenal sebagai pengobatan alternatif. Terapi komplementer telah diakui dan dapat dipakai sebagai pendamping terapi konvensional medis. Pada pelaksanaannya terapi komplementer dapat dilakukan bersamaan dengan terapi medis(Aprillia, Yesie \& Brenda Ritchmond. 2011).

Pelayanan kebidanan komplementer merupakan bagian dari penerapan pengobatan komplementer dan alternatif dalam tatanan pelayanan kebidanan. Pelayanan kebidanan merupakan bagian yang menyeluruh dari sistem pelayanan 
kesehatan yang diberikan oleh bidan yang telah diregistrasi. Pelayanan tersebut dapat dilakukan secara mandiri, kolaborasi dan rujukan kepada ibu hamil, ibu bersalin, ibu nifas, bayi baru lahir, dan anak, serta wanita usia reproduksi dan usia lanjut (Barnes et al. 2008).

Sejumlah negara sudah menerapkan terapi komplementer dan alternatif sebagai pendukung pengobatan konvensional. Walaupun di Indonesia belum ada UndangUndang yang mengatur secara khusus tentang pelaksanaan pelayanan kebidanan komplementer, namun penyelenggaraan pengobatan komplementer secara umum telah diatur dalam Keputusan Menteri Kesehatan No.1109/Menkes/Per/IX/2007 tentang pengobatan komplementer alternatif.

Pelayanan kebidanan komplementer merupakan pilihan bagi bidan maupun perempuan untuk mengurangi intervensi medis saat hamil dan melahirkan serta masa nifas, dan berdasarkan pengalaman hal tersebut cukup membantu. Namun, sebagian besar terapi ini tidak dianggap bermakna dalam pengobatan konvensional. Hal ini disebabkan oleh kelangkaan dalam hal bukti klinis dan informasi yang diterbitkan sehubungan dengan efektivitas pelayanan kebidanan komplementer pada kehamilan, persalinan dan nifas. (Ernst\&Watson, 2012)

Pelaksanaan pelayanan kebidanan komplementer di Indonesia tidak hanya dilakukan oleh sektor swasta/mandiri, namun juga pemerintah (Puskesmas dan Rumah Sakit). Akan tatapi, pelaksanaan pada sektor pemerintah terhambat prosedur tetap yang masih harus mengacu pada pelayanan kebidanan konvensional, sehingga pelaksanaan pelayanan kebidanan komplementer lebih banyak dijumpai pada sektor swasta. Dengan demikian pengaruh informasi yang beredar di masyarakat sangat menentukan pemanfaatan terapi komplementer, terutama pada masa nifas dimana masyarakat mengacu kepada kebiasaan dan budaya setempat.

Terapi komplementer yang ada menjadi salah satu pilihan pengobatan masyarakat, termasuk di Jambi yang masih cukup kental dengan budaya. Jika pemanfaatannya tepat, maka terapi komplementer pada ibu nifas dapat membantu pemulihan ibu, namun tidak sedikit juga klien yang memanfaatkan terapi komplementer yang tidak sesuai dengan kesehatan.

Di berbagai tempat pelayanan kesehatan tidak sedikit klien bertanya tentang terapi komplementer atau alternatif pada petugas kesehatan seperti dokter, bidan ataupun perawat. Untuk itu klien membutuhkan informasi yang tepat tentang pemilihan terapi komplementer dalam masa nifas sehingga aman untuk diaplikasikan sesuai dengan kebutuhan.

Penelitian membuktikan bahwa terapi komplementer dapat menjadi solusi untuk mengurangi rasa ketidaknyamanan bahkan dapat menyembuhkan beberapa penyakit. Terapi ini lebih aman dan memiliki risiko yang lebih rendah dibandingkan dengan obat modern dengan bahan kimia. namun terkadang terdapat juga pasien yang menggunakan pengobatan tradisional atau komplementer tetapi tidak mendapatkan kesembuhan sesuai harapan bahkan menjadikan penyakitnya lebih parah. Untuk itu perlu dipahami tentang pemanfaatan terapi komplementer karena meskipun pengobatan komplementer relatif lebih aman namun bukan berarti tidak menimbulkan risiko (Barnes et al. 2008).

Di Indonesia saat ini menggunakan istilah pelayanan kesehatan tradisional, alternatif dan komplementer, dimana pelayanan kesehatan tradisional merupakan seluruh pelayanan yang ada di masyarakat, terbagi dalam 2 kelompok besar yaitu pelayanan kesehatan tradisional ramuan dan pelayanan kesehatan tradisional keterampilan. Hal yang berkembang saat ini adalah pelayanan kesehatan alternatif dan 
komplementer dimaksudkan sebagai pelayanan yang sudah dinyatakan aman dan bermanfaat serta dapat diintegrasikan dalam fasilitas pelayanan kesehatan (Ernst, Edzard \& Watson, Leala. 2012).

Ibu nifas merupakan kelompok yang dianjurkan memanfaatkan terapi atau pengobatan komplementer dalam mengatasi keluhan yang dirasakan, karena dengan terapi komplementer dapat menghindari efek samping pengobatan konvesional dan memiliki kontrol yang besar terhadap kesehatan sendiri. Adapun pelayanan terapi komplementer dalam masa nifas diantara :

a. Herbal

b. Aromaterapi

c. Hipnobreastfeeding

d. Yoga pospartum

e. Pijat oksitosin

Pemanfaatan terapi komplementer dipengaruhi oleh media massa, informasi dari sebuah produk, rekomendasi keluarga dan teman, sifat alami manusia yang ingin selalu mencoba hal-hal baru serta kemudahan akses pada pengobatan ini dapat mempengaruhi persepsi seseorang untuk menggunakan terapi komplementer karena dinilai alami dan aman digunakan (( Kwan,2010).

Terapi komplementer dalam masa nifas merupakan salah satu alternatif non medis yang dapat dimanfaatkan oleh ibu dalam mengatasi keluhan dan pemulihan selama nifas karena dapat menghindari efek samping dari penggunaan obat-obatan dan bahan kimia. Tidak sedikit ibu nifas melakukan praktik tradisional yang kurang tepat dan merugikan kesehatannya karena kurangnya pengetahuan ibu tentang terapi tradisional atau komplementer yang tepat.

Pemanfaatan terapi komplementer dalam masa nifas harus diawasi dan dipastikan aman bagi proses pemulihan ibu serta produksi ASI sehingga tidak menimbulkan efek negatif baik pada ibu maupun bayi. Sementara informasi tentang pemanfaatan terapi komplementer yang tepat masih jarang diterima oleh masyarakat, terutama yang bersumber dari tenaga kesehatan, termasuk pada ibu hamil di wilayah kerja Puskesmas Putri Ayu Kota Jambi sebagai puskesmas dengan sasaran ibu hamil terbanyak di Kota Jambi.

\section{TARGET DAN LUARAN}

Proses pemulihan setelah persalinan merupakan proses yang alamiah dimana ibu akan mengalami berbagai perubahan pada fisiologisnya yang akan berdampak juga pada psikologisnya. Terapi komplementer dapat menjadi salah satu alternatif yang aman dalam mengatasi keluhan dan menjaga stamina serta pemulihan ibu selama masa nifas, namun perlu pengawasan dalam pemanfaatannya agar terjamin aman untuk ibu maupun pengeluaran ASI. Untuk itu diperlukan pendidikan kesehatan kepada ibu hamil agar dapat memilih terapi komplementer yang aman bagi pemulihannya saat masa nifas nanti.

Melalui pendidikan kesehatan tentang terapi komplementer dalam masa nifas diharapkan terjadi peningkatan pengetahuan dan sikap ibu hamil dalam memanfaatkan terapi komplementer tersebut sehingga dapat dimanfaatkan dengan aman untuk ibu dan bayi pada masa nifas nanti.

\section{METODE PELAKSANAAN}

Kegiatan pengabdian masyarakat ini berupa pendidikan kesehatan kepada ibu hamil tentang terapi komplementer dalam masa nifas yang dilaksanakan pada bulan April sampai Agustus tahun 2020 di Puskesmas Putri Ayu.

Sasaran dalam kegiatan ini adalah ibu hamil di Puskesmas Putri Ayu. Adapun kontribusi sasaran dalam pengabdian masyarakat ini adalah menjadi peserta kegiatan pengabdian, mengikuti pre dan post-test dan mendapatkan informasi tentang terapi komplementer dalam masa nifas yang aman. 
Tahapan pelaksanaan kegiatan pengabdian kepada masyarakat ini adalah sebagai berikut:

1. Kegiatan awal/persiapan

a. Mengkaji dan menganalisis data

b. Mengidentifikasi masalah

c. Menyusun proposal kegiatan pengabdian kepada masyarakat

d. Menyusun SAP dan materi serta mendasain leaflet terapi komplementer untuk disampaikan kepada sasaran

e. Menyiapkan lembar pre-test dan posttest tentang terapi komplementer dalam masa nifas

f. Mengurus izin lokasi pengabdian kepada masyarakat

2. Pelaksanaan kegiatan

a. Perkenalan antara tim pengabdian kepada masyarakat dengan sasaran

b. Penjelasan kegiatan yang akan dilakukan dalam melibatkan sasaran

c. Memberikan lembar pre-test

d. Melaksanakan peer education meliputi memberikan materi tentang terapi komplementer dalam masa nifas menggunakan leaflet.

e. Memberikan lembar post-test

f. Penutupan

3. Penyusunan laporan dan publish jurnal pengabmas

a. Merumuskan hasil pengabdian kepada masyarakat

b. Mengumpulkan dokumentasi dan lampiran yang mendukung (daftar hadir, foto-foto, dan surat-surat)

c. Membuat jurnal pengabmas dan melakukan publish jurnal

d. Menyerahkan laporan kepada tim PPPM

\section{HASIL PEMBAHASAN}

Kegiatan pengabdian kepada masyarakat ini dilaksanakan bersamaan dengan kegiatan Praktik Klinik Kebidanan Komprehensif mahasiswa D III Kebidanan Stikes Baiturrahim. Dalam kegiatan ini dilakukan pemberian pendidikan kesehatan berkaitan dengan perubahan fisiologis dan psikologis pada masa nifas dan pemanfaatan terapi komplementer untuk pemulihan masa nifas dan menudukung proses laktasi serta diskusi tentang terapi komplementer yang dilarang untuk ibu nifas.

Setelah dilakukan pendidikan kesehatan, dilakukan diskusi tentang terapi komplementer yang boleh dan tidak boleh dilakukan pada ibu nifas. Diharapkan ibu hamil pada saat nifas nanti dapat memanfaatkan terapi komplementer dengan bijak dan sesuai dengan manfaat kesehatannya sehingga ibu dapat lebih cepat pulih serta mampu memberikan ASI sesuai kebutuhan bayinya.

Pengabdian kepada masyarakat ini melibatkan 1 orang mahasiswa yang pada saat bersamaan juga sedang melaksanakan Praktik Klinik Komprehensif di poli KIA Puskesmas Putri Ayu.

Setelah dilakukan pendidikan kesehatan tentang terapi komplementer masa nifas pada ibu hamil, dilakukan evaluasi secara lisan, didapatkan hasil :

a) Ibu mengerti perubahan fisiologis dan psikologis pada masa nifas

b) Ibu memahami bahwa terapi komplementer dapat dimanfaatkan dalam mempercepat pemulihan serta mendukung proses menyusui

c) Ibu mengetahui terapi komplementer yang aman dan yang tidak aman untuk ibu nifas.

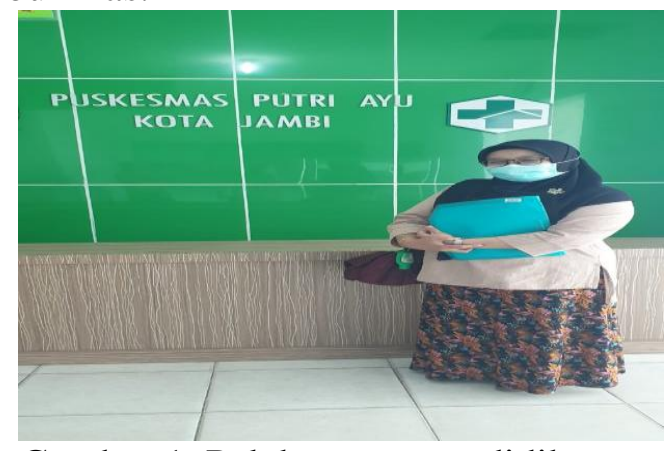

Gambar 1. Pelaksanaan pendidikan kesehatan tentang terapi komplementer pada masa nifas 
Pengetahuan tentang terapi komplementer dipengaruhi oleh berbagai sumber informasi, diantaranya media massa, informasi dari sebuah produk, rekomendasi keluarga dan teman, sifat alami manusia yang ingin selalu mencoba hal-hal baru serta kemudahan akses pada terapi komplementer ( Kwan,2010).

Pemanfaatan terapi komplementer pada ibu nifas sangat dipengaruhi oleh pengalaman. Pengalaman merupakan sumber pengetahuan atau pengalaman merupakan suatu cara memperoleh kebenaran pengetahuan (Moyad $\mathrm{M}$ dan Hawks JH. 2009).

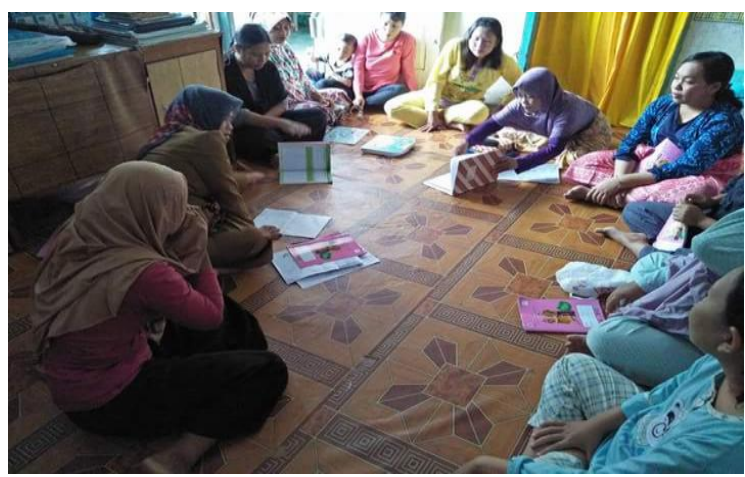

Gambar 2. Pendidikan kesehatan tentang terapi komplementer pada masa nifas

Pengetahuan tentang terapi komplementer dipengaruhi oleh berbagai sumber informasi, diantaranya media massa, informasi dari sebuah produk, rekomendasi keluarga dan teman, sifat alami manusia yang ingin selalu mencoba hal-hal baru serta kemudahan akses pada terapi komplementer( Kwan,2010).

Pelayanan kebidanan komplementer merupakan pilihan bagi bidan maupun perempuan untuk mengurangi intervensi medis saat hamil dan melahirkan serta masa nifas, dan berdasarkan pengalaman hal tersebut cukup membantu. Namun, sebagian besar terapi ini tidak dianggap bermakna dalam pengobatan konvensional. Hal ini disebabkan oleh kelangkaan dalam hal bukti klinis dan informasi yang diterbitkan sehubungan dengan efektivitas pelayanan kebidanan komplementer pada kehamilan, persalinan dan nifas (Moyad M dan Hawks JH. 2009).

Salah satu keluhan yang dialami oleh ibu nifas yaitu nyeri perineum. Penanganan untuk mengurangi nyeri perineum dapat dilakukan secara farmakologi dan non farmakologi namun penggunaan secara farmakologi sering menimbulkan efek samping dan kadang tidak memiliki kekuatan efek yang diharapkan. Aromaterapi digunakan sebagai salah satu alternatif penanganan nyeri non farmakologik. Berbagai macam aroma terapi yang dapat digunakan antara lain cendana, kemangi, kayumanis, kenanga, sitrus, melati, cengkih, sering digunakan untuk mengurangi rasa nyeri yaitu terapi komplementer aromaterapi dengan minyak essensial lavender, karena lavender mempunyai sifat-sifat antikonvulsan, antidepresi, anxiolytic, dan bersifat menenangkan(Onyiapat, 2011)

Saat aromaterapi dihisap, zat aktif yang (kelenjar hipofise) untuk mengeluarkan hormon endorpin. Endorpin diketahui sebagai zat yang menimbulkan rasa tenang, relaks dan bahagia. acetate yang terdapat dalam lavender berefek sebagai analgetik (Peraturan Menteri Kesehatan RI,2007).

Totok wajah juga merupakan terapi salah satu komplementer yang berguna untuk mengurangi stress dan kecemasan. Penekanan pada titik- titik akupuntur pada wajah bertujuan untuk mengirim sinyal yang menyeimbangkan sistem syaraf atau melepaskan bahan kimia seperti endorfin yang mengurangi rasa sakit dan stress. Totok wajah juga dapat dimanfaatkan sebagai terapi komplementer dalam menurunkan kecemasan ibu nifas, baik karena perubahan yang dialaminya maupun kecemasan yang timbul akibat proses menyusui yang belum lancar. Penurunan kecemasan yang dialami setelah totok wajah terjadi karena pijatan pada meridian (pembuluh darah sekunder) pada wajah bisa melancarkan sirkulasi darah (Pamuji 2014). 
Pijat pada ibu nifas juga merupakan salah satu terapi pendukung yang efektif untuk mengurangi ketidaknyamanan fisik serta memperbaiki gangguan mood. Hasil intervensi pada penelitian Pamuji et al (2014) didapat bahwa kombinasi metode pijat woolwich dan endorphine berpengaruh terhadap peningkatan kadar hormon prolaktin dan volume ASI ibu postpartum (Trionngo, 2013)

\section{KESIMPULAN DAN SARAN 1. Kesimpulan}

Setelah diberikan pendidikan kesehatan tentang terapi komplementer dalam masa nifas didapatkan peningkatan pengetahuan ibu nifas tentang terapi komplementer dalam meningkatkan pemulihan ibu selama nifas serta mendukung proses menyusui sehingga ibu menjalani masa nifas dengan nyaman dan proses laktasi sukses memenuhi kebutuhan bayinya.

\section{Saran}

Ibu nifas umumnya akan mengalami perubahan dan ketidaknyamanan fisiologis maupun psikologis dalam proses pemulihan alat-alat reproduksinya, sehingga mendorong ibu untuk mengatasinya dengan berbagai cara baik medis maupun non medis, termasuk terapi komplementer. Untuk itu perlu edukasi yang komprehensif dari petugas kesehatan agar ibu nifas dapat memilih terapi komplementer yang tepat dan aman. Tenaga kesehatan hendaknya memasukkan informasi tentang terapi komplementer dalam asuhan rutin dalam kehamilan trimester III sehingga ibu siap memanfaatkan terapi komplementer dengan tepat pada masa nifas.

\section{UCAPAN TERIMAKASIH}

Tim pengabdian kepada masyarakat mengucapkan terimakasih yang sebesarbesarnya kepada Stikes Baiturrahm Jambi atas dana dan fasilitas serta surat izin dalam melakukan pengabdian kepada masyarakat ini dan juga kepada Kepala Puskesmas Putri Ayu beserta jajarannya yang telah memberikan izin tempat melakukan pengabdian masyarakat ini sehingga kegiatan ini berjalan dengan lancar. Demikian juga ucapan terima kasih kepada ibu hamil peserta pengabdian kepada masyarakat yang telah bersedia mengikuti rangkaian kegiatan ini.

\section{DAFTAR PUSTAKA}

Aprillia, Yesie \& Brenda Ritchmond. 2011. Gentle Birth "Melahirkan Nyaman Tanpa Rasa Sakit”. Jakarta: Gramedia

Barnes et al. 2008. Complementary and Alternative Medicine Use Among Adults and Children: United States. Journal of National Center for Health Statistics. USA

Ernst, Edzard \& Watson, Leala. 2012. Midwives' use of complementary/ Alternative Treatments: Midwifery Journal, Volume 28, Issue 6, Ed: December 2012, Pages 772-777

Koensoemardiyah. 2009. Aromaterapi untuk Kesehatan dan Kecantikan. Yogyakarta: Lily Publisher

Kwan, H.K. 2010. Totok Aural Wajah Meridian 312 Cantik, Gramedia Pustaka Utama, Jakarta

Moyad M dan Hawks JH. 2009. Complementary and Alternative Therapies, dalam Black JM dan Hawks JH. Medical-Surgical Nursing: Clinical Management for Positive Outcomes (8th Edition). Sl: Elsevier Saunders

Onyiapat et al. 2011. Complementary and Alternative Medicine Use Among Adults in Enugu, Nigeria. Journal of Nursing: Department of Nurisng Sciences College of Medicine University of Nigeria

Peraturan Menteri Kesehatan RI, No. : 1109/Menkes/Per/IX/2007 tentang penyelenggaraan pengobatan komplementer-alternatif di fasilitas pelayanan kesehatan. 
Pamuji, Supriyana, Rahayu. 2014. Pengaruh kombinasi Metode Pijat Evidence-Based Woolwich dan Endorphine terhadap Kadar Hormon Prolaktin dan Volume ASI (Studi Pada Ibu Postpartum di Griya Hamil Sehat Mejasem Kabupaten Tegal). Vol 6 NO 1 BHAMADA, TITK

Tournaire M, Theau-Yonneau A. 2007. Complementary and Alternative Approaches to Pain Relief during

Labor.

rn Med

Trionggo, I., dkk., 2013, Panduan Sehat Sembuhkan Penyakit dengan Pijat dan Herbal. Indotoleransi:Yogyakarta

Widaryanti, Rahayu. 2019. Terapi Komplementer Pelayanan Kebidanan Berdasarkan Bukti Scientific dan Empiris. Yogyakarta: Deepublish 